\title{
DIET AND SERUM PROTEIN LEVELS OF URBAN ZULU ADULTS
}

\author{
BY \\ J. H. ABRAMSON,* B. GAMPEL, ${ }^{*}$ N. SCOTCH, $\uparrow$ AND C. SLOME \\ From the Department of Social, Preventive, and Family Medicine, University of Natal, Durban, South Africa, and the \\ Department of Sociology and Anthropology, Washington State University, Pullman, Washington
}

The serum protein pattern of Africans is usually found to differ from that of Europeans, being characterized by lower albumin levels and higher total globulin levels. There is evidence that this may be due to a number of possibly interrelated factors, viz. parasitism, malnutrition, liver disease, and, to a limited extent, genetic considerations. There is no unambiguous evidence that diet plays a major role in producing the characteristic African serum protein pattern.

Various epidemiological studies have indicated the probable importance of diet. Studies in Durban (Powell, 1958), Uganda (Holmes, Stanier, and Thompson, 1955), and Salisbury (Gelfand, 1958) have shown that African male nurses, students, and hospital orderlies, who partake of a relatively good diet, tend to have higher albumin levels and lower globulin levels than other African groups. Further, it has been shown that West Africans domiciled in Britain tend to show a rise in their serum albumin levels, and after some years a limited drop in their initially high serum globulin levels (Schofield, 1957). Similarly, a rise has been found in the serum albumin levels of African students after a few months in residence at Makerere College (Holmes, 1954).

In each of these instances, however, the dietary differences were accompanied by a variety of other

\footnotetext{
* Department of Social, Preventive, and Family Medicine, University of Natal, Durban.

t Washington State University, Pullman, Washington. Work done during the tenure of a Research Fellowship of the U.S. Public Health Service (under the sponsorship of Jeremiah Stamler, M.D., formerly assistant Director of the Cardiovascular Department [Louis M. Katz, assistant Director of the Cardiovascular Department [Louis M. Katz,
M.D., Director] of the Medical Research Institute, Michael Reese Hospital, at present Director, Heart Disease Control Program, Chicago Board of Health [Herman N. Bundeson, M.D., President]). This work was supported in part by a supplementary grant (H 4197-SI) from the National Heart Institute of the U.S. Public Health Service. It is a pleasure to acknowledge the guidance and support of Professor M. J. Herskovits, Chairman, and the Program of African Studies, Northwestern University. The financial assistance of Washington State University is also appreciated.

‡ Present address: Hebrew University-Hadassah Medical School, Jerusalem.
}

environmental differences, which might largely account for these protein changes. In particular, there were probably variations in the disease load, as a result of differences in exposure to infection or in the treatment of illnesses.

There is some evidence, too, indicating that diet may not be of major importance. Holmes and others (1955) were unable to correlate differences in the serum protein patterns of persons living in different parts of Uganda with differences in their diet, and Edozien (1957) found no evidence of a relationship with diet in adult Nigerians, either in comparisons of persons classified according to income, or in a short-term feeding experiment. In respect of Durban Africans, it has been argued that protein malnutrition cannot directly explain their serum protein pattern, and the possibility has been suggested that this pattern may be a reflection of amoebic, bilharzial, helminthic, or other infestation or infection (Joubert, Hookins, and Hunter, 1959).

This report deals with an investigation of the relationship between diet and serum protein levels in a group of ethnically homogeneous Africans living in a single neighbourhood, under fairly uniform conditions of housing and exposure to infection. The main cereal eaten in this community is maize, which contributes slightly over 50 per cent. of the average caloric intake. The usual diet includes relatively small quantities of green or yellow vegetables, milk, meat, and fish (Kark and Chesler, 1950). There is a high prevalence of malnutrition. Intestinal helminthiasis and respiratory infections are common. Apart from amoebiasis and bilharzia, which are not uncommon, tropical diseases are rare, and malaria has been uncommon in Durban since 1936 (Medical Officer of Health, Durban, 1930-1957). Aspects of the health and way of life of this community have been described more fully elsewhere (Gampel, 1960; Kark, 1957; Kark and Chesler, 1956). 
The data were collected in the course of a broader nutrition-hypertension study project, which was carried out in October-December, 1958, on a population sample of the Zulu adults residing in a housing scheme for Africans in the city of Durban. There is a considerable uniformity in this area, in respect of housing, sanitary facilities, and the availability of health services. The persons examined were drawn from a 1 in 7 sample of the homes in the area. The sampling method used and the characteristics of the sample are fully described elsewhere (Abramson, Gampel, Slome, and Scotch, 1960). Most of the persons examined, though currently living in the city, had been born in rural areas. All had some skin or mucosal signs of malnutrition. Schistosomal ova were not found in the urine in any case.

The following results are based on the findings in 89 men and 158 women aged 20 to 64 years. Persons with major illnesses (tuberculosis, congestive cardiac failure, diabetes, and hemiplegia) were excluded from the study, as were pregnant women, and women within 6 months of their last pregnancy.

\section{MethodS}

\section{DieTARy Assessment}

Each subject was asked how many times a week he or she usually consumed meat/fish, eggs, fruit, dried legumes, green/yellow vegetables, tshwala ("kaffir beer"), and spirits. A further series of questions dealt with the consumption of milk, either as a beverage, in other beverages, with porridge, or as amasi (sour milk). By the use of conversion factors based on an unpublished dietary study of the community (Kark and Chesler, 1950), it was possible to express approximate milk consumption in terms of pints per week. The average number of teaspoonsful of sugar consumed per day, in beverages or with porridge, was used as an approximate index of sugar consumption.

The diets of persons having 5 or more pints of milk a week, and/or meat/fish daily were rated as "superior", and other diets as "inferior". Diets rated as "superior" were found to be characterized also by a greater consumption of eggs, fruit, green/yellow vegetables, and sugar.

\section{Serum Protein Estimation}

With few exceptions, blood was collected by the method of venepuncture described by Hill and Buckle (1956), in order to minimize the risk of haemolysis. Specimens were submitted for serum protein estimation, using the biuret method of
Weichselbaum (1946). The reproducibility of results was assessed by performing 21 tests on a single blood specimen, over a period of 13 days. The standard deviations of the results were $0.33 \mathrm{~g}$. per cent. for total protein $(5.6$ per cent. of the mean value) and $0.41 \mathrm{~g}$. per cent. for albumin $(11.9$ per cent. of the mean value). Globulin values, which are affected both by errors in the total protein estimation and by those in the albumin estimation, showed a lower reproducibility, the standard deviation being $0.41 \mathrm{~g}$. per cent. $(16 \cdot 1$ per cent. of the mean value). Though these findings indicated that the reproducibility of results was not high, the scatter of the albumin findings recorded for the persons examined did not appear to be unduly great. The standard deviation of the albumin results was $0.45 \mathrm{~g}$. per cent. in the male sample, and $0.34 \mathrm{~g}$. per cent. in the female sample. The corresponding figures for two male Durban African groups studied by Powell (1958), using the same method of estimation, were 0.29 and $0.56 \mathrm{~g}$. per cent. The standard deviation of the globulin observations was higher $-0.59 \mathrm{~g}$. per cent. for men and $0.58 \mathrm{~g}$. per cent. for women, both values being higher than Powell's $(0.37$ and $0.31 \mathrm{~g}$. per cent.).

It was subsequently found that our total protein and albumin levels were unduly low, because of the use of defective protein standards. In view of this bias in the findings, it is apparent that our results in respect of absolute serum protein levels cannot be compared with those of other investigators. We do not consider, however, that the presence of a consistent bias of this sort affects the validity of comparisons of different categories of persons within our sample. Because of these technical deficiencies however, our conclusions can be regarded only as suggestive, rather than as definitive.

\section{OTHER DATA}

On the basis of interview data, the approximate mean household monthly income per capitem and household food expenditure per capitem were calculated for each person. Social class ratings were based on a classification developed at the Institute of Family and Community Health (Kark, Chesler, and Abramson, 1951; Kark, 1953). Experience of rural versus urban living was assessed by asking "Where did you live for most of your childhood (to the age of 16)?" and "How long have you been living in an urban area?" The answer to this latter question was expressed as a percentage of the subject's age. Occasional questions were inadvertently left unasked in the course of interviews. Where information 
was lacking, the person concerned was excluded from the relative analysis.

\section{RESULTS}

The mean albumin level of the men was $2 \cdot 87 \mathrm{~g}$. per cent (S.D. $0.45 \mathrm{~g}$. per cent.), and of the women 2.74 g. per cent. (S.D. 0.34 g. per cent.). As stated above, the true values for both groups are probably somewhat higher. The mean globulin level of the men was 3.57 g. per cent. (S.D. 0.59 g. per cent.), and of the women $3.75 \mathrm{~g}$. per cent. (S.D. $0.58 \mathrm{~g}$. per cent.).

In both sexes, evidence was found of an association between serum protein levels and diet. Among the men, the consumption of an "inferior" diet was associated with low albumin and high globulin levels. The mean serum albumin level of the 51 men taking an "inferior" diet was $2.78 \mathrm{~g}$. per cent. (S.D. 0.42 g. per cent.), and that of the 37 men taking a "superior" diet was $2.98 \mathrm{~g}$. per cent. (S.D. 0.41 g. per cent.). The mean serum globulin level of the former group was 3.69 g. per cent. (S.D. 0.60 g. per cent.), and that of the latter $3 \cdot 40 \mathrm{~g}$. per cent. (S.D. $0.54 \mathrm{~g}$. per cent.). The differences between these mean values were significant $(\mathrm{P}<0.05)$. Of the 51 men taking an "inferior" diet, 38 ( 74.5 per cent.) had serum albumin levels of under $3 \mathrm{~g}$. per cent. and sixteen (31.4 per cent.) had globulin levels of $4 \mathrm{~g}$. per cent. or more. Among the 37 men taking a "superior" diet, the corresponding figures were eighteen ( 48.6 per cent.) and three ( 8.1 per cent.). These differences were significant $(P<0.05$ and $<0.02$ respectively). Among the women, there was a similar association, not with the consumption of a "superior" or "inferior" diet, but with the frequency with which meat/fish was eaten. Women who did not consume meat/fish daily tended to have low albumin and high globulin levels. Of 135 such women, 37 $(27.4$ per cent.) had albumin levels of under $2 \cdot 5 \mathrm{~g}$. per cent. and $45(33.3$ per cent.) had globulin levels of $4 \mathrm{~g}$. per cent. or more. Of the 22 women who took meat/fish daily, the corresponding figure was two (9.1 per cent.) in each instance. The difference was significant only in respect of globulin levels $(P<0.05)$. Similar significant associations were present, among the women, between high globulin levels and a low intake of green/yellow vegetables, and a high intake of sugar or dried legumes $(\mathrm{P}<0.05,<0.02$, and $<0.02$ respectively). These were probably interrelated associations, as women taking meat/fish frequently, tended to take green/ yellow vegetables frequently, and dried legumes infrequently.
There were a number of other relationships in both sexes between protein levels and the intake of specific food items; these, however, fell just short of statistical significance. There was no relationship between protein levels and reported alcohol consumption.

There was some degree of association between the current diet and various aspects of the subjects' background. The consumption of "inferior" diets, for example, was commoner among men of Social Class V (unskilled labourers), and among those whose childhood had been predominantly rural. Accordingly the relationship between serum protein levels and diet was re-examined, keeping constant a variety of such features of the subjects' current or past life situation. The findings in respect of the men are shown in the Table (opposite). When income, food expenditure, education, rurality, social class, and household size were held constant, the association of "inferior" diets with low albumin and high globulin levels remained apparent in each instance, with a single minor exception, and in a number of instances attained statistical significance in spite of the small size of the groups compared. These findings indicated that the association between serum protein levels and diet was independent of the listed features of the subject's backgrounds. The significant relationship between the women's globulin levels and their diet could not be examined in this way, as parity constituted a further variable (Gampel, Abramson, Slome, and Scotch, 1960) which, when held constant, reduced the groups compared to very small numbers.

The men taking "superior" and "inferior" diets respectively did not appear to differ appreciably in their exposure to infection in or around their homes. In both groups, there was a considerable and similar degree of crowding in the home, as shown by their respective mean crowding indices (number of persons in the household divided by the number of bed- and living-rooms). The mean index for the men taking a "superior" diet was $2 \cdot 6$, and that for the men taking an "inferior" diet, $2 \cdot 5$. Further, children were present in most homes in both groups. Not only do children tend to expose the adults in a home to respiratory infection (Badger, Dingle, Feller, Hodges, Jordan, and Rammelkamp, 1953), but in this community, where many children defaecate in the open outside their dwellings, they are likely to expose adults to faecal-borne infestation as well. 94 per cent. of the men taking a "superior" diet had chilren aged 12 years or less in their homes, and 96 per cent. of those taking an "inferior" diet. The corresponding figures for children aged 6 or less were 86 and 90 per cent. respectively. As a third 
TABLE

ASSOCIATION BETWEEN DIET AND SERUM PROTEIN LEVELS IN MEN (BACKGROUND FACTORS HELD CONSTANT)

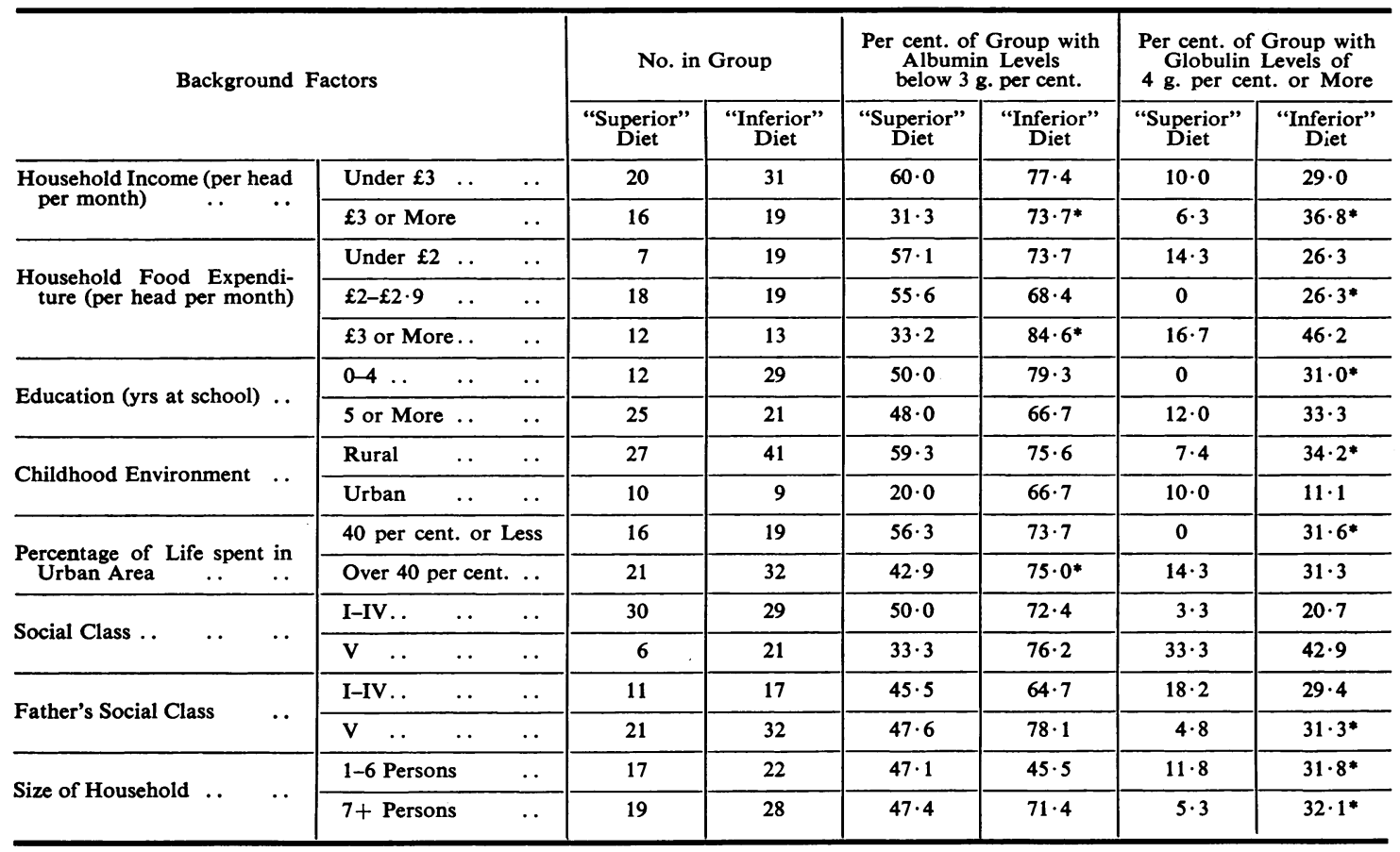

* Significantly higher $(\mathrm{P}<0.05)$ than the corresponding values for men consuming a "superior" diet. Significance was tested by using the tables provided by Armsen (1955) or by $\chi^{2}$ tests (with Yates' correction) where these Tables were not applicable.

index of the men's exposure to domestic infection, an extraction of the occurrence of ascariasis in their households was made from the clinical files of the Institute of Family and Community Health, which provides a health service to this community. The occurrence of this infestation was regarded as an indicator of exposure to faecal-borne infection. In the homes of 61 per cent. of the men having a "superior" diet, ascariasis was diagnosed in one or more members of the household within 2 years of this study. The corresponding figure for the other group was 57 per cent. These figures, which were based not on a systematic survey, but on clinical records, were certainly an underestimate of the true prevalence in both groups.

Figures were available for the men's attendances at the Institute of Family and Community Health, though not for their use of other medical services. The percentages who had attended the Institute for care in 1957 or 1958 were 33 per cent. (of the "superior" diet group) and 41 per cent. (of the "inferior" diet group); the median number of attendances per man (for those attending) was 1 and 2 respectively.

\section{Discussion}

Our findings suggest a relationship between serum protein patterns and diet. Men taking an "inferior" diet and women taking meat or fish infrequently, for example, tended to have low serum albumin and high serum globulin levels. The possibility must, however, be considered that these serum protein findings are expressions, direct or indirect, not of dietary factors, but of some other factor or factors occurring in association with certain dietary patterns. However, the association between serum protein patterns and diet appeared to be independent of social class, rurality, and a number of other features of our subjects' current and past life situation.

In view of the possible significance of infestations and infections in producing the characteristic serum protein pattern of Africans in Durban (Joubert and others, 1959), it is necessary to give close consideration to the possibility that the men taking "superior" and "inferior" diets respectively differed in their levels of infection. Although both groups of men were free of obvious disease, they might differ, particularly in the occurrence, nature, or severity of gastro-intestinal or respiratory infections, the 
commonest infections in this community, or in their bowel parasite loads. An association between diet and levels of infection might arise in three ways: the two groups of men might differ in their exposure to infection, in their susceptibility or response to infection, or in the extent to which they used medical services.

There appeared to be little difference between the men taking "superior" and "inferior" diets in their exposure to infections outside their homes; the men in both groups lived in the same community, in homes scattered through the housing scheme, and used the same public transport services. With regard to domestic infection, they lived in similar homes, with similar sanitary facilities. The evidence indicated, moreover, that exposure to infection in or around the home was probably similar for the two groups. It was probable that there was considerable current and recent exposure of both groups to bowel and respiratory infections, but there was no suggestion of differences between the two groups. With regard to their past exposure to infection, there is no reason to believe that the men currently having a "superior" diet had, in the more remote past, been less exposed to infection. It is noteworthy that the relationship between the men's current diet and their serum protein levels appeared to be independent of their experience of rural or urban living. The figures for attendances at the Institute of Family and Community Health do not suggest that the men having a "superior" diet used medical services more effectively. It thus appears unlikely that the two dietary groups of men differed appreciably in their exposure to infection, or in their use of medical services.

The possibility cannot be excluded that there was in fact a difference in the levels of infection of the two groups, resulting from the effects of their nutrition on their susceptibility or response to infection. This possibility receives support from the fact that although there is considerable evidence that diet alone can reduce serum albumin levels, there is very limited experimental evidence of a globulin-raising effect. Thus while the low albumin levels of the men taking an "inferior" diet may well be a direct effect of their diet, it is not improbable that their raised globulin levels may be an indirect effect, resulting for example from the influence of their diet on their state of infection. One possibility worthy of consideration is that the current diet may, by its effect on the flora and fauna of the gut, indirectly affect serum protein levels, by influencing either the availability or absorption of nutrients, or the production of antibody-carrying globulins. This possibility receives some support from studies of apparently normal Indian students, which showed, on the one hand, a relationship between vegetarianism and high serum gamma globulin levels, and on the other, a tendency for the administration of antibiotics to produce a rise in serum albumin and a fall in serum globulin levels (Satoskar and Lewis, 1954, 1955; Dhopeshwarkar, Trivedi, Kulkarni, Satoskar, and Lewis, 1956).

In general, it can be concluded that our findings strongly suggest that the serum protein findings in our subjects were expressions, at least to some extent, either of dietary factors or of factors which are influenced by diet, such as hepatic pathology, or possibly, susceptibility or response to infection.

It is not possible, on the basis of the crude dietary measures used, to pinpoint the precise dietary factors which may have influenced our subjects' serum protein patterns. Associations were found, in one sex or both, between low albumin or high globulin levels and "inferior" diets, a low consumption of meat/fish and green/yellow vegetables, and a high consumption of sugar and dried legumes. In the absence of full quantitative dietary data it is not justifiable, however, to draw conclusions implicating particular foodstuffs or nutrients. It is interesting, in view of the known association between alcohol consumption and hepatic disease, that no evidence was found of a relationship between alcohol intake and serum protein levels.

It is not suggested that the current diet alone is responsible for the serum protein pattern found. It has been shown (Keys, Brožek, Henschel, Mickelsen, and Taylor, 1950) that protein deprivation alone does not markedly affect the serum protein fractions of previously healthy persons. It is likely that the association found between current diet and serum protein levels is dependent on the predisposing effects of our subjects' prior experience of nutrition and infection.

Caution should be used in generalizing from our findings to African groups in which malaria and other major tropical diseases are prevalent.

\section{SUMMARY}

Among a population sample of urban Zulu adults, it was found that differences in serum albumin and globulin levels were significantly related to their current diet. Men whose diets included little milk, meat, or fish tended to have low serum albumin and high serum globulin levels. Of men taking such "inferior" diets, 74.5 per cent. had serum albumin levels of under $3 \mathrm{~g}$. per cent. and 31.4 per cent. had serum globulin levels of $4 \mathrm{~g}$. per cent. or more. 
Among men taking "superior" diets, the corresponding figures were $48 \cdot 6$ and $8 \cdot 1$ per cent. This relationship with diet appeared to be independent of income, social class, childhood rurality, housing, exposure to infection, and a number of other features of the current or past life situation of the subjects.

The findings suggested that the serum protein levels of the subjects were expressions, at least in part, of their diet, or of factors which are influenced by diet.

We are indebted to our subjects, to Nursing Sisters C. C. Majola and T. Triegaardt, Medical Recorders W. H. Pietersen, S. J. Maharaj, and A. Ngcobo, and other members of the staff of the Institute of Family and Community Health, Durban, and Mr. N. Mdlazi for their assistance, and to Drs. S. M. Joubert and S. J. Powell, of the Medical Faculty, and Mr. S. M. A. Meggitt, of the Department of Mathematics, Natal University, for their advice and criticism.

\section{REFERENCES}

Abramson, J. H., Gampel, B., Slome, C., and Scotch, N. (1960). Amer. J. clin. Nutr. (In press). Armsen, P. (1955). Biometrika, $42,494$.
Badger, G. F., Dingle, J. H., Feller, A. E., Hodges, R. G., Jordan, W. S., and Rammelkamp, C. H. (1953). Amer. J. Hyg., 58, 41.

Dhopeshwarkar, G. A., Trivedi, J. C., Kilkarni, B. S., Satoskar, R. S., and Lewis, R. A. (1956). Brit. J. Nutr., 10, 105.

Edozien, J. C. (1957). J. clin. Path., 10, 276.

Gampel, B. (1960): "The Lamontville Community Health Service". A waiting publication.

Awaiting publication. Slome, C., and Scotch, N. (1960). Amer. J. clin. Autr. (In press).

clin. Nutr. (In press).
Gelfand, M. (1958). Leech., 28, 49.

Hill, J. W. and Buckle, G. C. (1956). Sth Afr. J. med. Lab. Technol., 2, No. 3,7 .

Holmes, E. G. (1954). In "Malnutrition in African Mothers, Infants, and Young Children". Report on Second Inter-African (C.C.T.A.) Conference on Nutrition, Gambia, 1952. H.M.S.O., London.

, Stanier, M. W., and Thompson, M.D. (1955). Trans. roy. Soc. trop. Med. Hyg., $49,376$.

Joubert, S. M., Hookins, K. W., and Hunter, W. G. (1959). Sth Afr. Lab clin Med. 5 , 1

Lab. clin. Med., 5, 1.
Kark, E. (1953). Sth Afr. J. clin. Sci., 4, 23.

Kark, S. L. (1957). Sth Afr. J. Lab. clin. Med., 3, 101

and Chesler, J. (1950). Dietary Study of an Urban African Community (unpublished).

- (1956). Sth Afr. J. Lab. clin. Med., 2, 134.

, and Abramson, E. G. (1951). "A Modified Social Class Classification". Proceedings of the Institute of Family and Community Health, Durban. (Mimeo)

Keys, A., Brežek, J., Henschel, A. Mickelsen, O., and Taylor, H. L. (1950). "The Biology of Human Starvation". University of Minnesota Press, Minneapolis.

Medical Officer of Health, City of Durban (1930-1957). Annual Reports.

Powell, S. J. (1958). Sth Afr. J. Lab. clin. Med., 4, 273

Satoskar, R. S., and Lewis, R. A. (1954). Antibiot. and Chemother., 4, 1152.

(1955). Indian J. med. Res., 43, 415.

Schofield, F. D. (1957). Trans. roy. Soc. trop. Med. Hyg., 51, 332. Weichselbaum, T. E. (1946). Amer. J. clin. Path., 16: Tech. Bull., 7, p. 40. 